\title{
Microsurgical clipping of middle cerebral artery aneurysms: complications and risk factors for complications
}

Thomas METAYER ( $\nabla$ thomas.metayer@neurochirurgie.fr)

Centre Hospitalier Universitaire de Caen https://orcid.org/0000-0002-5956-4770

Arthur Leclerc

Alin Borha

University Hospital of Caen

Stephane Derrey

University Hospital of Caen

Olivier Langlois

University Hospital of Rouen

Charlotte Barbier

University Hospital of Caen

Sorin Aldea

Rothschild Foundation Hospital

Caroline le guerinel

Rothschild Foundation Hospital

Michel Piotin

Rothschild Foundation Hospital

Denis Vivien

Normandie Univ, UNICAEN

Anaiis R. Briant

University Hospital of Caen

Evelyne Emery

University Hospital of Caen

Thomas Gaberel

University Hospital of Caen

\section{Research Article}

Keywords: middle cerebral artery, aneurysms, microsurgery

Posted Date: November 18th, 2021 
DOI: https://doi.org/10.21203/rs.3.rs-1048020/v1

License: (c) (1) This work is licensed under a Creative Commons Attribution 4.0 International License. Read Full License 


\section{Abstract \\ Objective}

Middle cerebral artery aneurysms (MCAas) with rupture and unruptured IAs are considered good candidates for microsurgery. The objective of the present study was to evaluate the risk of complications and the risk factors for microsurgical treatment of MCAas to better define the indications for microsurgery.

\section{Methods}

We conducted a retrospective cohort study based on data provided from three French tertiary neurosurgical units from January 1, 2013 to May 31, 2020. We first collected data on all the patients who required microsurgical treatment for MCAas. We evaluated the frequency of complications and finally searched for the risk factors for complications after microsurgery. Complications were defined as a composite criterion with the presence of one of the following: procedural-related death, symptomatic cerebral ischemia, impossible exclusion, incomplete exclusion, or (re)bleeding of the treated aneurysm and symptomatic surgical site hematoma. We then compared patients with and without complications using univariate and multivariate analyses.

\section{Results}

Between January 2013 and May 2020, 292 MCAas in 284 patients were treated. A total of 29 (9.9\%) MCAas had a complication. The complications were as follows: symptomatic cerebral ischemia: $4.8 \%$, aneurysm rebleeding: $0.3 \%$, surgical site hematoma: $1.0 \%$, impossible exclusion: $0.3 \%$, and incomplete exclusion: $4.1 \%$. However, severe complications, defined as death or a modified Rankin score (mRs) score $\geq 4$ at 3 months, were infrequent and occurred in $7 / 292$ patients (2.4\%). In the multivariate analysis, independent risk factors for complications were the following: a ruptured aneurysm, a larger maximum IA size, a larger neck size, and arterial branches passing less than $<1 \mathrm{~mm}$ from the IA neck or dome.

\section{Conclusions}

MCAa surgery is a safe procedure with a low rate of serious procedure-related complications and an excellent rate of occlusion. The risk factors for complications are a ruptured aneurysm, a larger IA, a larger neck size, and the presence of an "en passage" arterial branch less than $1 \mathrm{~mm}$ from the IA. In these cases, at least for factors that do not present a significant difficulty for EVT, such as the presence of an "en passage" artery or ruptured IA, EVT has to be more thoroughly discussed.

\section{Introduction}


Middle cerebral artery aneurysms (MCAa) represents $20 \%$ of all intracranial aneurysms (IA). [2] There are two options for treating IA: microsurgery and endovascular therapy (EVT). [2] There is much controversy surrounding the best treatment modality to exclude IA. $[4,13,20]$ In ruptured IAs, when both modalities are possible, endovascular coiling is the preferred method. $[13,20]$ For unruptured IAs, both treatments can be proposed.[4] However MCA aneurysms represent a specific subgroup of IA: they are located distally from the Willis polygon and often have wide necks.[9] They are subsequently considered as good candidates for microsurgery in ruptured and unruptured IAs. $[1,6,14,16]$ The objective of the present study was to evaluate the risk factor of complications in microsurgical treatment of MCA aneurysm, to better define the indications of microsurgery.

\section{Methods}

This cohort study has been reported in accordance with the STROBE statements (www.strobestatement.org). The study was reviewed and approved by the Institutional Ethics Committee of Caen University Hospital (Caen, France).

\section{Setting and study design}

We conducted a retrospective cohort study based on data provided from three French tertiary neurosurgical units (University Hospital of Caen, Rouen and Foundation Adolphe de Rothschild, Paris). We first collected all the patients who required microsurgical treatment for MCAa. Then, we evaluated the frequency of complications and finally we search for risk factors of complications after microsurgery.

\section{Participants}

All adult patients ( $\geq 18$ years old) admitted to the three hospitals for the treatment of a MCAa, either a ruptured or an unruptured IA, from January 1, 2013 to May 31, 2020 were screened. Follow-up was stopped on August 31,2020. We included in the final analysis all the patients who required microsurgical treatment during the same period of time. All ruptured aneurysms were treated, if possible, within 48 hours after ictus. For unruptured IAs, the choice of treatment was based on several variables, including aneurysm size and form, patient age, risk factor for rupture, and treatment risk.[8] Each case was discussed by a multidisciplinary staff, and if treatment was decided, it was presented to the patient, who had to choose to be treated or not.[23] If a patient had 2 aneurysms, the treatment for each aneurysm was analysed separately.

\section{Surgery for MCAa}

All MCAa surgeries were conducted by an experienced neurovascular surgeon in each centers $(\geq 50 \mathrm{MCA}$ aneurysms treated). Ruptured aneurysm were managed according to a predefined protocol following current recommendations.[23] A standard pterional for ruptured IA and a mini pterional craniotomy for unruptured IA was commonly performed. When a hematoma was associated, it was removed; then the sylvian fissure was opened and the aneurysm was clipped. 


\section{Variables}

\section{IA treatment procedure-related complications}

The treatment complications were evaluated by two investigators who were not blinded of the treatment received. Complications was defined as a composite criterion with the presence of one of the following: procedural-related death; symptomatic cerebral ischemia defined as the presence of cerebral infarction on the CT or MR scan 48 hours after aneurysm occlusion associated to a correspondent neurological symptom; impossible exclusion; incomplete exclusion (Raymond-Roy=3) ${ }^{14}$; (re)bleeding of the treated aneurysm and symptomatic surgical site haematoma. We also looked at severe complications defined as death or an mRs score $\geq 4$ at 3 months.

\section{Risk factor for treatment complications: clinical characteristics}

In the included patients, the following clinical characteristics were retrospectively reviewed: age; sex; history of chronic high blood pressure (HBP); active smoking; familial form, personal history of IA (ruptured or unruptured), IA's status (ruptured or unruptured), the WFNS score and ASA score $\geq 3$.

\section{Risk factor for treatment complications: radiological characteristics}

Similarly, the following radiological characteristics were retrospectively reviewed: the IA location (M1, bifurcation or $>\mathrm{M} 2)$, the length of $\mathrm{M} 1$ segment $(\mathrm{mm})$ defined as the extending horizontally along the sphenoid wing, the neck's size $(\mathrm{mm})$ and the maximum depth of the IA, the aspect ratio (defined as the maximum perpendicular height of the aneurysm divided by the average neck diameter of the aneurysm), the presence of a bifurcation or trifurcation, the presence of "en passage" artery within $1 \mathrm{~mm}$ of the IA (Figure 2), the presence of an IA calcification on the CT-scan and the presence of aneurysm's thrombosis. For ruptured IAs, we also collected the Fisher's score, the presence of intra ventricular hematoma (IVH) and/or intraparenchymal haematoma (IPH).

\section{Risk factor for treatment complications: per procedural data}

The characteristics of the technics used during the surgery were retrospectively reviewed:

Doppler and intraoperative indocyanine green angiography (ICG), temporary clipping and its duration, intraoperative rupture and the clipping method. Simple clipping was defined as the application of a single clip at aneurysm's neck, remodelling was defined as the application of several clip in different directions.

\section{Statistical analysis}

The baseline characteristics were described by the mean (std) or the median (IQR) for quantitative variables according to their distribution and by the number (frequency) for qualitative variables. To 
identify potential risk factors of complications, univariate analyses were performed using the Student $t$ test or the Mann-Whitney test for quantitative variables according to their normal distribution or not, and using the $\mathrm{Chi}^{2}$ test or the Exact Fisher test for qualitative variables. All variables associated significantly with complications on univariate analysis $(p<0.05)$ were considered for inclusion in the multivariate logistic regression analysis. We explored collinearity among these potential risk factors by calculating the variance inflation factor (VIF), with a value above 5 indicating collinearity. We used a backward procedure among qualified variables for selecting independent risk factors associated with complications, with the threshold of $p<0.10$ to remain in the model.

All analyses were conducted in the complete-case analysis. Statistical significance was set at the 0.05 level. Statistical analysis was performed with SAS software V9.4 (SAS institute, NC, Cary).

\section{Results}

\section{Baseline characteristics (Table 1 and figure 1)}


Table 1

Baseline characteristics of the patients treated by microsurgery for MCA aneurysms. Comparison between patients who had a complication related to the surgery and those who did not.

\section{Baseline characteristics \\ Clinical characteristics}

$\begin{array}{ll}\text { All } & \begin{array}{l}\text { No complication } \\ \text { group }\end{array} \\ (\mathrm{N}=292) & (\mathrm{n}=263)\end{array}$

Complication group value $(n=29)$

\begin{tabular}{|c|c|c|c|c|}
\hline Age, mean \pm std & $\begin{array}{l}52.7 \\
\pm 10.8\end{array}$ & $52.6 \pm 10.8$ & $53.3 \pm 10.8$ & 0.733 \\
\hline Female sex, n (\%) & $212(73)$ & $193(73)$ & $19(66)$ & 0.368 \\
\hline HBP, n (\%) & $118(40)$ & $106(40)$ & $12(41)$ & 0.911 \\
\hline Active smoking, $\mathrm{n}(\%)$ & $130(45)$ & $117(44)$ & $13(45)$ & 0.972 \\
\hline$A S A \geq 3, n(\%)$ & $35(12)$ & $31(12)$ & $4(14)$ & 0.763 \\
\hline Familial form, n (\%) & $16(6)$ & $16(6)$ & $0(0)$ & 0.383 \\
\hline $\begin{array}{l}\text { History of unruptured aneurysm, } n \\
(\%)\end{array}$ & $19(7)$ & $19(7)$ & $1(3)$ & 0.705 \\
\hline History of ruptured aneurysm, n (\%) & $25(9)$ & $23(9)$ & $2(7)$ & 1.000 \\
\hline Ruptured aneurysm, n (\%) & $124(42)$ & $101(38)$ & $23(79)$ & $<0.001$ \\
\hline \multicolumn{5}{|l|}{ Fisher score, n (\%) } \\
\hline $1-3$ & $45(36)$ & $39(39)$ & $6(26)$ & \multirow[t]{2}{*}{0.260} \\
\hline 4 & $79(64)$ & $62(61)$ & $17(74)$ & \\
\hline \multicolumn{5}{|l|}{ WFNS score, n (\%) } \\
\hline $1-3$ & $85(69)$ & $72(71)$ & $13(57)$ & \multirow[t]{2}{*}{0.169} \\
\hline $4-5$ & $39(31)$ & $29(29)$ & $10(43)$ & \\
\hline $\begin{array}{l}\text { Intraventricular hematoma (IVH), } \\
\mathrm{n}(\%)\end{array}$ & $45(36)$ & $37(37)$ & $8(35)$ & 0.868 \\
\hline $\begin{array}{l}\text { Intraparenchymal hematoma } \\
(\mathrm{IPH}), \mathrm{n}(\%)\end{array}$ & $58(47)$ & $44(44)$ & $14(61)$ & 0.134 \\
\hline
\end{tabular}

\section{Radiological characteristics}

IA Location, $\mathrm{n}(\%)$
M1
$18(6)$
$15(6)$
$3(10)$
0.348

* missing data (from 1 to 11 missing data)

HBP: High blood pressure; IA: Intracranial aneurysm; 


\begin{tabular}{|c|c|c|c|c|}
\hline Baseline characteristics & $\begin{array}{l}\text { All } \\
(\mathrm{N}=292)\end{array}$ & $\begin{array}{l}\text { No complication } \\
\text { group } \\
(n=263)\end{array}$ & $\begin{array}{l}\text { Complication } \\
\text { group } \\
(n=29)\end{array}$ & $\begin{array}{l}\text { p- } \\
\text { value }\end{array}$ \\
\hline Bifurcation & $262(89)$ & $236(90)$ & $26(90)$ & \\
\hline$>\mathrm{M} 2$ & $12(4)$ & $12(5)$ & $0(0)$ & \\
\hline $\begin{array}{l}\text { M1 segment length }(\mathrm{mm}) \text {, mean } \pm \\
\text { std }\end{array}$ & $\begin{array}{l}19.2 \pm \\
-3.7\end{array}$ & $19.4 \pm 3.6$ & $17.4 \pm 3.9$ & 0.007 \\
\hline Neck size $(\mathrm{mm})$, mean \pm std * & $\begin{array}{l}3.93 \pm \\
1.76\end{array}$ & $3.78 \pm 1.49$ & $5.29 \pm 3.06$ & 0.016 \\
\hline Sac/Neck ratio, mean \pm std * & $\begin{array}{l}1.77 \pm \\
0.77\end{array}$ & $1.73 \pm 0.71$ & $2.17 \pm 2.17$ & 0.062 \\
\hline IA maximum size $(\mathrm{mm})$, mean $\pm \mathrm{std}$ * & $\begin{array}{l}6.52 \pm \\
3.1\end{array}$ & $6.15 \pm 2.72$ & $9.83 \pm 4.58$ & $<0.001$ \\
\hline Multilobed shape, $\mathrm{n}(\%)$ * & $102(36)$ & $90(35)$ & $12(43)$ & 0.395 \\
\hline Calcification on CT scan, n (\%)* & $10(3)$ & $8(3)$ & $2(7)$ & 0.254 \\
\hline Thrombosed aneurysm, n (\%)* & $8(3)$ & $6(2)$ & $2(7)$ & 0.178 \\
\hline Bifurcation, $\mathrm{n}(\%)$ & $238(82)$ & $215(82)$ & $23(79)$ & 0.749 \\
\hline Trifurcation, n (\%) & $54(19)$ & $48(18)$ & $6(21)$ & 0.749 \\
\hline Branches $<1 \mathrm{~mm}, \mathrm{n}(\%)^{*}$ & $131(45)$ & $112(43)$ & $19(66)$ & 0.023 \\
\hline \multicolumn{5}{|c|}{ * missing data (from 1 to 11 missing data) } \\
\hline HBP: High blood pressure; IA: Intrac & I aneury & & & \\
\hline
\end{tabular}

Between January 2013 and May 2020, 292 MCAa in 284 patients were treated. The mean age was $52.7 \pm$ 10.8 years. $168(58 \%)$ were unruptured and $124(42 \%)$ were ruptured. In the ruptured cohort, there was a high prevalence of WFNS $1-3(n=85 ; 69 \%)$ and Fisher $4(n=79 ; 64 \%)$ patients. Most MCA were bifurcation $(n=238 ; 82 \%)$ and almost all MCAa were on this bifurcation $(n=262 ; 89 \%)$. Treatment strategies included primary clipping in 195 (67\%) and remodelling in 96 (33\%). Temporary clipping was used in 32 (11\%) MCAa clipping (Table 2). 
Table 2

Surgical techniques used to treat MCA aneurysms. Comparison between patients who had a complication related to the surgery and those who did not.

\begin{tabular}{|c|c|c|c|c|}
\hline Surgical techniques & $\begin{array}{l}\text { All } \\
(\mathrm{N}=292)\end{array}$ & $\begin{array}{l}\text { No complication } \\
\text { group } \\
(n=263)\end{array}$ & $\begin{array}{l}\text { Complication } \\
\text { group } \\
(n=29)\end{array}$ & $\begin{array}{l}\mathrm{p}- \\
\text { value }\end{array}$ \\
\hline \multicolumn{5}{|l|}{ Type of surgery, $n(\%)$ * } \\
\hline Simple clipping & $\begin{array}{l}195 \\
(67)\end{array}$ & $178(68)$ & $17(59)$ & \multirow[t]{2}{*}{0.312} \\
\hline Remodeling & $96(33)$ & $84(32)$ & $12(41)$ & \\
\hline Temporary clipping, $n(\%)^{\star}$ & $32(11)$ & $23(9)$ & $9(35)$ & $<0.001$ \\
\hline $\begin{array}{l}\text { Temporary clipping duration, } \\
\text { median (IQR) }\end{array}$ & $\begin{array}{l}5(2 \\
-10)\end{array}$ & $5(2-10)$ & $8(4-11)$ & 0.363 \\
\hline Intraoperative rupture, $\mathrm{n}(\%)^{\star}$ & $39(14)$ & $28(11)$ & $11(42)$ & $<0.001$ \\
\hline Intraoperative Doppler, n (\%)* & $70(24)$ & $66(26)$ & $4(14)$ & 0.253 \\
\hline ICG, $\mathrm{n}(\%)^{*}$ & $\begin{array}{l}166 \\
(57)\end{array}$ & $149(58)$ & $17(59)$ & 0.929 \\
\hline \multicolumn{5}{|c|}{ *missing data (from 1 to 11 missing data) } \\
\hline ICG: Indocyanine green angio & & & & \\
\hline
\end{tabular}

\section{MCAa treatment: complications (Figure 1)}

A total of 29 (9.9\%) MCAa had a complication. Clinical complications were as follows: symptomatic cerebral ischemia (14/29; $48.3 \% ; 4.8 \%$ of the whole cohort), aneurysm's rebleeding $(1 / 29 ; 3.5 \% ; 0.3 \%$ of the whole cohort) and surgical site hematoma $(3 / 29 ; 10.3 \% ; 1.0 \%$ of the whole cohort). Radiological complications were: impossible exclusion $(1 / 29 ; 3.5 \% ; 0.3 \%$ of the whole cohort) and incomplete exclusion $(12 / 29 ; 41.4 \% ; 4.1 \%$ of the whole cohort). Two MCAa had symptomatic cerebral ischemia and incomplete exclusion.

However severe complications, defined as death or a mRs score $\geq 4$ at 3 months, were infrequent and occurred in $7 / 292$ patients (2.4\%). Among them there was 5 ruptured IAs with 2 deaths $(0.7 \%)$ and 3 symptomatic cerebral ischemia (1\%); and 2 unruptured IA complicated by a severe symptomatic cerebral ischemia (0.7\%).

\section{Risk factors of complications}

To define risk factors of complications, we compared patients without complications $(n=263)$ to patients with complications ( $n=29)$ (Table 1). In univariate analysis, the clinical characteristics were not significantly different between the two groups, except for the ruptured status ( $38 \%$ had a ruptured aneurysm in the No Complication group versus $79 \%$ in the Complication group, $p<0.001)$. Concerning the 
radiological characteristics, the maximum aneurysm's size and the neck's size were larger in the Complication group than in the No Complication group with $9.8 \pm 4.6 \mathrm{~mm}$ versus $6.1 \pm 2.7 \mathrm{~mm}(\mathrm{p}<0.001)$ and $5.3 \pm 3.1 \mathrm{~mm}$ versus $3.8 \pm 1.5 \mathrm{~mm}(\mathrm{p}=0.016)$, respectively. There were however no differences concerning the aspect ratio $(p=0.062)$. Interestingly, shorter M1 segment was a risk factor of complication, with a length of $17.4 \pm 3.9 \mathrm{~mm}$ in the complication group versus $19.4 \pm 3.6 \mathrm{~mm}$ in the no complication group $(p=0.007)$. Similarly, "en passage" branches $<1 \mathrm{~mm}$ were more common in the complications group ( $66 \%$ versus $43 \%$ respectively, $p=0.023)$.

Regarding the surgical techniques and event (Table 2): temporary clipping and intraoperative rupture were risk factors of complications ( $35 \%$ in complication group versus $9 \%$ in no complication group, $p<0.001$; $42 \%$ versus $11 \%, \mathrm{p}<0.001$; respectively).

No collinearity was found between the selected covariates for the multivariate model. In the multivariate analysis, four significant independent risk factors of complications after IA treatment were identified: the ruptured aneurysm $(\mathrm{aOR}=11.0295 \% \mathrm{Cl}[2.97-40.88], \mathrm{p}<0.001)$, the IA maximum size $(\mathrm{aOR}=1.2795 \% \mathrm{Cl}$ [1.10 - 1.48], $p=0.002)$, the neck size $(a O R=1.4895 \% \mathrm{Cl}[1.08-2.01], p=0.015)$ and the branches $<1 \mathrm{~mm}$ $(\mathrm{aOR}=3.0895 \% \mathrm{Cl}[1.01-9.35], \mathrm{p}=0.048)$ also adjusted for the intraoperative rupture, the temporary clipping and the $\mathrm{M} 1$ segment length (Table 3 ).

Table 3

Risk factors for complications by multivariate logistic regression using backward selection ( $N=267: 25$ complications).

\begin{tabular}{|llll|}
\hline Risk factors & aOR & $95 \%$ Cl & p-value \\
\hline Ruptured aneurysm & 11.02 & {$[2.97-40.88]$} & $<0.001$ \\
\hline Intraoperative rupture & 3.18 & {$[0.98-10.31]$} & 0.055 \\
\hline Neck size $(\mathrm{mm})$ & 1.48 & {$[1.08-2.01]$} & 0.015 \\
\hline IA Maximum size $(\mathrm{mm})$ & 1.27 & {$[1.10-1.48]$} & $\mathbf{0 . 0 0 2}$ \\
\hline Branches < 1 mm & 3.08 & {$[1.01-9.35]$} & $\mathbf{0 . 0 4 8}$ \\
\hline $\begin{array}{l}\text { aOR: adjusted Odds Ratio, 95\% Cl: 95\% Confidence interval, and p-value of multivariate logistic } \\
\text { regression also adjusted for temporary clipping and M1 segment length. }\end{array}$ \\
\hline
\end{tabular}

\section{Discussion}

\section{Main results}

In this multicentric retrospective cohort, our first results showed that the risk of complications of microsurgical clipping of MCAa, based on a composite primary endpoint, is moderate as it occurs in $9.9 \%$ of patients. Moreover, severe complications, with a $\mathrm{mRS} \geq 4$ occurs in only $2.4 \%$. These complications 
mainly occur on ruptured MCAa. Radiological risk factors were MCAa with larger maximum size and neck size. An "En passage" arterial branch located at less than $1 \mathrm{~mm}$ from the IA was also a risk factor.

For the surgical techniques, the temporary clipping and intraoperative rupture were significantly at risk of complication in univariate model, but these associations no longer remained in multivariate model.

\section{Interpretation}

The first and maybe the biggest risk factor of complication of MCAa clipping is the ruptured status of the IA. This fact is well documented in the literature, $[2,3,13,14,23]$ and is related to more difficult dissection because of the hiding effect of the subarachnoid blood, because of a possible brain oedema limiting the sylvian fissure opening, and finally to the presence of a breach within the aneurysm wall, which increased the risk of intraoperative rupture.[12] Except for the breach within the IA wall, all these pitfall are not an issue for endovascular treatments, and therefore may explain the benefit of EVT over surgery in the ISAT trial. Overall, our results in the ruptured cohort are very similar from the one reported in the BRAT study of MCAa.[14]

A large size $(9.8 \mathrm{~mm}$ versus $6.1 \mathrm{~mm})$ and the neck size $(5.3 \mathrm{~mm}$ versus $3.8 \mathrm{~mm})$ of the aneurysm are risk factors of complications. This association is also renowned in the literature: larger aneurysm, and larger neck are significantly harder to clip than small aneurysm with wide neck. [10, 22]

Although not significant in multivariate, shorter M1 segment are already known as a risk factor of intraoperative premature rupture of MCAa.[15] The shorter the M1 segment is, the higher the risk of premature rupture before proximal vascular control increases, and such premature rupture can lead to clinical complication. Another explanation relies on the fact that in the case of a short M1 segment, MCAa and especially its neck is located deeper in the sylvian fissure, so close to the lenticulostriate arteries which increases the ischemic risk.

The fact that "En passage" arteries branches located less than $1 \mathrm{~mm}$ from the neck or the dome is a risk factor of complication is to our knowledge not yet described in the literature. These branches in contact with the IA may interfere with the placement of the clip. Ischemic risk is therefore increased, first because if they are not well dissected from the IA they can be caught in the clip. At the opposite, when they are deeply adherent to the neck or to some part of the dome, avoiding the clip placement, they have to be dissected, which increases the risk of intraoperative rupture. However, the presence of "en passage" arterial branch on the pre-operative imaging does not mean systematically that the artery will be significantly stuck in the IA, thus representing a surgical difficulty. Sometimes the artery is only stuck in the IA without adhesion. Unfortunately, no radiological index allows us to predict the adhesion of the branches to the IA.

Intraoperative rupture is also a risk factor of complications in univariate analysis. It is an ever-present, unpredictable danger leading to unfavorable outcome. $[7,15,18]$ Similarly, temporary clipping is also a risk factor of complication in the univariate analysis. This is probably related to a confusion bias: temporary clipping is used when neck dissection is difficult, to prevent rupture during surgery, or when an 
intraoperative rupture occurred. It is more likely the complexity of the aneurysm's clipping which is a risk factor rather than the use of temporary clip. This hypothesis is supported by the fact that temporary clipping was no longer a risk factor of complication in the multivariate analysis. Moreover, the fact that temporary clipping is not a risk factor of complication is well documented in the literature. $[5,11]$

The combined use of doppler with ICG appears to be a protective factor of complications in the literature, however we do not find such results. In fact, doppler use has entered daily practice since the prospective trial by Stendel et al. which revealed that intraoperative doppler was relevant to the surgical procedure in $20-40 \%$ of the case, and particularly for MCA aneurysm.[21] Concerning intraoperative ICG angiography, it has been shown that ICG led to a modification of the clip position in $15 \%$ of the cases. In daily practice we are convince that intraoperative doppler and ICG angiography are useful, however we are not able to demonstrate it probably because in the cases treated without intraoperative doppler, the surgeon could have spent more time and attention for visual examination after clip application, thus limiting the impact of intraoperative doppler in our study. In our opinion, they both have a significant impact on the risk of procedure related ischemia and aneurysm's exclusion especially when the surgery is performed by a young neurovascular surgeon.[17]

\section{Limitations}

Of course, we must acknowledge several limitations to the present study. First, its retrospective design is a limitation that can induce bias per se. Second, our definition of complication is a composite criterion which is not always clinically relevant. However, it seemed necessary to us because complications in this type of surgery are rare. Despite this, we have a low number of events and still probably lack the statistical power to determine all independent risk factors. Moreover, our radiological complications (Raymond-Roy=3) were those that led to retreatment and therefore had a direct clinical impact. Some study criteria can be questioned such as the length of M1 segment. Indeed, it is not uncommon to have numerous anatomical variations at this level, including for example an early and late bifurcation.[19] Perhaps, there is an operator effect because surgery was performed by only few surgeons at each centers. Notwithstanding, all surgeons had operated at least $50 \mathrm{MCAa}$.

There is maybe a selection bias for the use of intraoperative ICG angiography and doppler, as these technics may have been used only in complex cases. However, if this bias exists, it would only decrease the visible benefit of these technic, so its impact seems to us limited.

\section{Conclusion}

Surgery for ruptured and unruptured MCAa is a safe procedure, with a low rate of serious procedurerelated complications and an excellent rate of occlusion. The risk factors of complications are a ruptured aneurysm, a larger size of the IA, a larger neck's size, and the presence of "en passage" arterial branch at less than $1 \mathrm{~mm}$ of the IA. In these cases, at least for factors that are not a significant difficulty of EVT, like the presence of "en passage" artery, or in ruptured IA, EVT has to be more thoroughly discussed. 


\section{Declarations}

- Funding : Not applicable

- Conflicts of interest/Competing interests (include appropriate disclosures) : Not applicable

- Availability of data and material (data transparency) : Not applicable

- $\quad$ Code availability (software application or custom code): Not applicable

- Ethics approval (include appropriate approvals or waivers) : The study was reviewed and approved by the Institutional Ethics Committee of Caen University Hospital (Caen, France).

- Consent to participate (include appropriate statements) : Not applicable

- $\quad$ Consent for publication (include appropriate statements) : Yes

- Authors' contributions (All authors must be mentioned) : TM and TG wrote the manuscript ; TM, AL, $A B, O L, M P, C L G$ collected the data, ARB made the stats, EE, DV, CB, SR, SD, SA corrected the draft.

\section{References}

1. Berro DH, L'Allinec V, Pasco-Papon A, Emery E, Berro M, Barbier C, Fournier H-D, Gaberel T (2019) Clip-first policy versus coil-first policy for the exclusion of middle cerebral artery aneurysms. J Neurosurg $1-8$

2. Brisman JL, Song JK, Newell DW (2006) Cerebral aneurysms. N Engl J Med 355(9):928-939

3. Connolly ES, Rabinstein AA, Carhuapoma JR, et al (2012) Guidelines for the management of aneurysmal subarachnoid hemorrhage: a guideline for healthcare professionals from the American Heart Association/american Stroke Association. Stroke 43(6):1711-1737

4. Darsaut TE, Findlay JM, Magro E, et al (2017) Surgical clipping or endovascular coiling for unruptured intracranial aneurysms: a pragmatic randomised trial. J Neurol Neurosurg Psychiatry 88(8):663-668

5. Dhandapani S, Pal SS, Gupta SK, Mohindra S, Chhabra R, Malhotra SK (2013) Does the impact of elective temporary clipping on intraoperative rupture really influence neurological outcome after surgery for ruptured anterior circulation aneurysms?--A prospective multivariate study. Acta Neurochir (Wien) 155(2):237-246

6. van Dijk JMC, Groen RJM, Ter Laan M, Jeltema JR, Mooij JJA, Metzemaekers JDM (2011) Surgical clipping as the preferred treatment for aneurysms of the middle cerebral artery. Acta Neurochir (Wien) 153(11):2111-2117 
7. Elijovich L, Higashida RT, Lawton MT, Duckwiler G, Giannotta S, Johnston SC, Cerebral Aneurysm Rerupture After Treatment (CARAT) Investigators (2008) Predictors and outcomes of intraprocedural rupture in patients treated for ruptured intracranial aneurysms: the CARAT study. Stroke 39(5):1501-1506

8. Etminan N, Brown RD, Beseoglu K, et al (2015) The unruptured intracranial aneurysm treatment score: a multidisciplinary consensus. Neurology 85(10):881-889

9. Gibo H, Carver CC, Rhoton AL, Lenkey C, Mitchell RJ (1981) Microsurgical anatomy of the middle cerebral artery. J Neurosurg 54(2):151-169

10. Lawton MT, Spetzler RF (1995) Surgical management of giant intracranial aneurysms: experience with 171 patients. Clin Neurosurg 42:245-266

11. Malinova V, Schatlo B, Voit M, Suntheim P, Rohde V, Mielke D (2018) The impact of temporary clipping during aneurysm surgery on the incidence of delayed cerebral ischemia after aneurysmal subarachnoid hemorrhage. J Neurosurg 129(1):84-90

12. Meling TR (2011) Lawton's seven aneurysms: tenets and techniques for clipping. Neurosurgery 68(6):E1774

13. Molyneux AJ, Birks J, Clarke A, Sneade M, Kerr RSC (2015) The durability of endovascular coiling versus neurosurgical clipping of ruptured cerebral aneurysms: 18 year follow-up of the UK cohort of the International Subarachnoid Aneurysm Trial (ISAT). Lancet 385(9969):691-697

14. Mooney MA, Simon ED, Brigeman S, Nakaji P, Zabramski JM, Lawton MT, Spetzler RF (2018) Long-term results of middle cerebral artery aneurysm clipping in the Barrow Ruptured Aneurysm Trial. J Neurosurg 130(3):895-901

15. Park J, Son W, Park K-S, Kang D-H, Shin IH (2016) Intraoperative premature rupture of middle cerebral artery aneurysms: risk factors and sphenoid ridge proximation sign. J Neurosurg 125(5):12351241

16. Rodríguez-Hernández A, Sughrue ME, Akhavan S, Habdank-Kolaczkowski J, Lawton MT (2013) Current management of middle cerebral artery aneurysms: surgical results with a "clip first" policy. Neurosurgery 72(3):415-427

17. Roessler K, Krawagna M, Dörfler A, Buchfelder M, Ganslandt O (2014) Essentials in intraoperative indocyanine green videoangiography assessment for intracranial aneurysm surgery: conclusions from 295 consecutively clipped aneurysms and review of the literature. Neurosurg Focus 36(2):E7

18. Schramm J, Cedzich C (1993) Outcome and management of intraoperative aneurysm rupture. Surg Neurol 40(1):26-30 
19. Shapiro M, Raz E, Nossek E, Chancellor B, Ishida K, Nelson PK (2020) Neuroanatomy of the middle cerebral artery: implications for thrombectomy. J Neurointerv Surg. doi: 10.1136/neurintsurg2019-015782

20. Spetzler RF, McDougall CG, Zabramski JM, Albuquerque FC, Hills NK, Nakaji P, Karis JP, Wallace

RC (2019) Ten-year analysis of saccular aneurysms in the Barrow Ruptured Aneurysm Trial. J Neurosurg $1-6$

21. Stendel R, Pietilä T, Al Hassan AA, Schilling A, Brock M (2000) Intraoperative microvascular Doppler ultrasonography in cerebral aneurysm surgery. J Neurol Neurosurg Psychiatry 68(1):29-35

22. Sughrue ME, Saloner D, Rayz VL, Lawton MT (2011) Giant Intracranial Aneurysms: Evolution of Management in a Contemporary Surgical Series. Neurosurgery 69(6):1261-1271

23. Thompson BG, Brown RD, Amin-Hanjani S, et al (2015) Guidelines for the Management of Patients With Unruptured Intracranial Aneurysms: A Guideline for Healthcare Professionals From the American Heart Association/American Stroke Association. Stroke 46(8):2368-2400

\section{Figures}

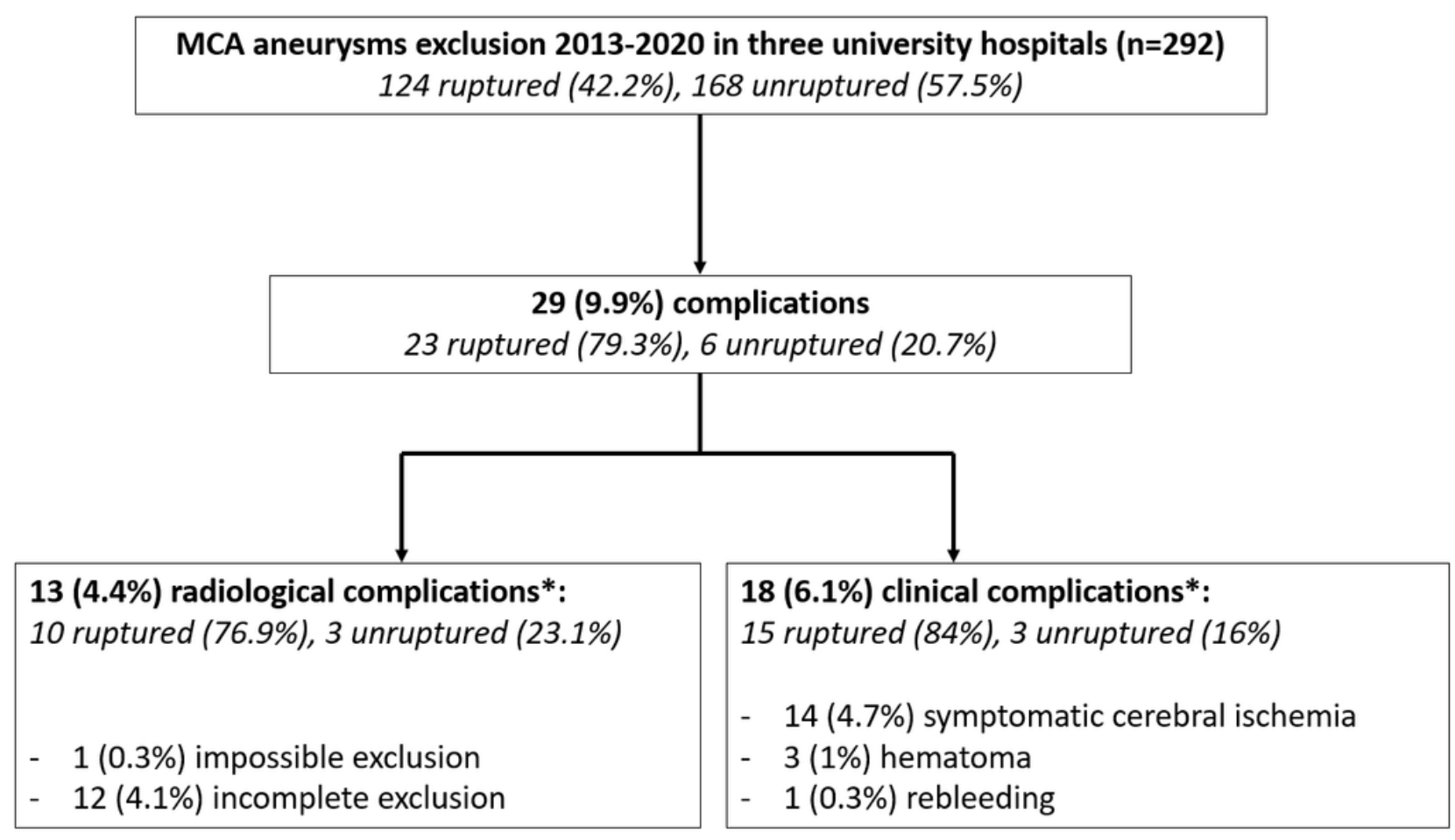

*2 aneurysms had symptomatic cerebral ischemia and incomplete occlusion

\section{Figure 1}


Flowchart of the study
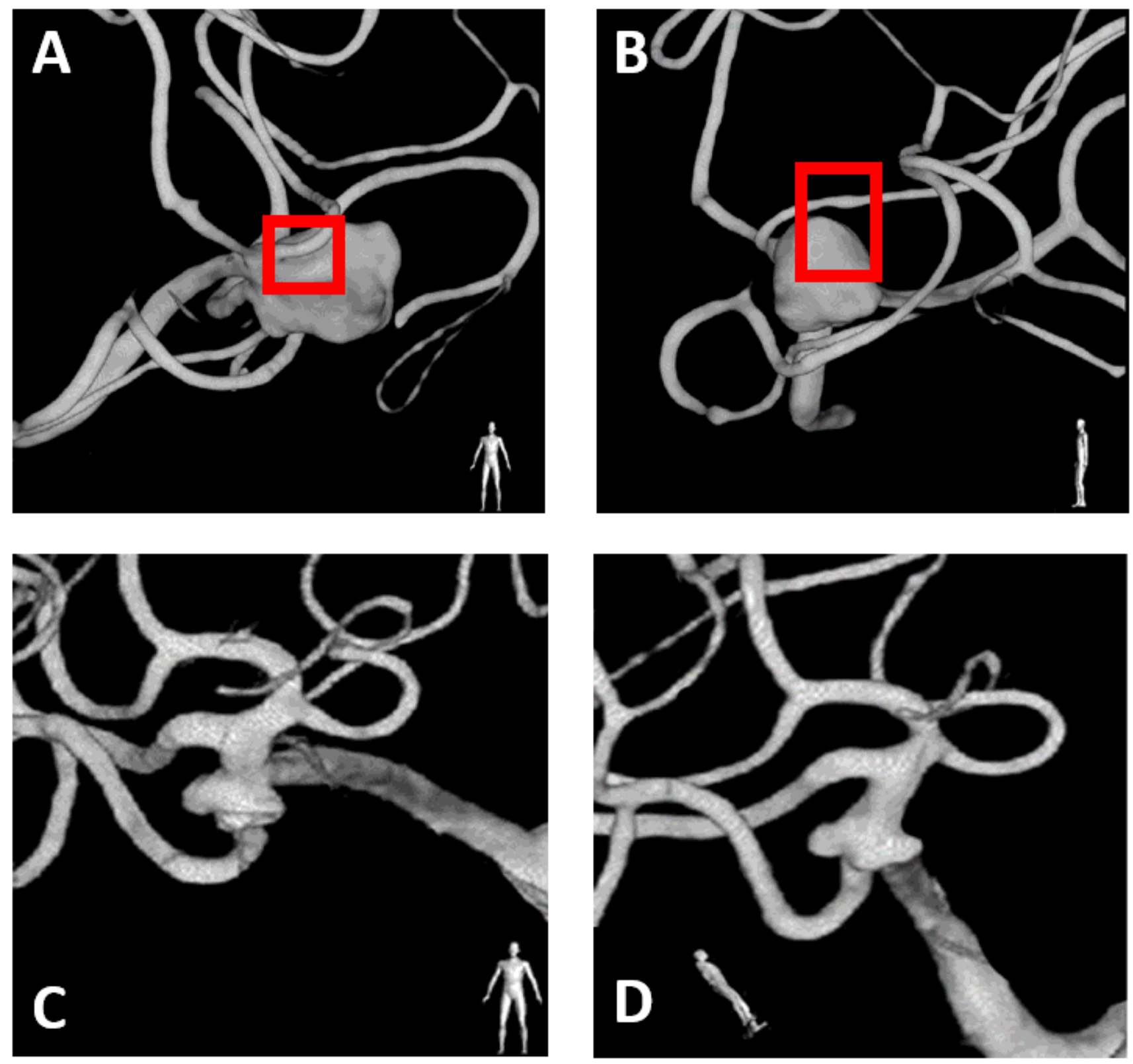

Figure 2

$A$ and $B$ : DSA showing an arterial branch passing within a millimeter of the aneurysm (red square). $C$ and D: DSA showing no arterial branch in contact with the aneurysm. 